Open Access

\title{
Zinc Lozenges May Shorten the Duration of Colds: A Systematic Review
}

\author{
Harri Hemilä
}

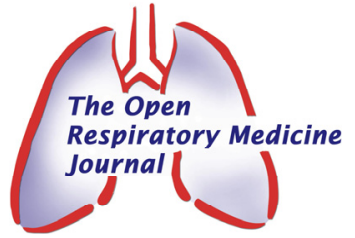

Department of Public Health, University of Helsinki, Helsinki, Finland

\begin{abstract}
Background: A number of controlled trials have examined the effect of zinc lozenges on the common cold but the findings have diverged. The purpose of this study was to examine whether the total daily dose of zinc might explain part of the variation in the results.

Methods: The Medline, Scopus and Cochrane Central Register of Controlled Trials data bases were searched for placebocontrolled trials examining the effect of zinc lozenges on common cold duration. Two methods were used for analysis: the P-values of the trials were combined by using the Fisher method and the results of the trials were pooled by using the inverse-variance method. Both approaches were used for all the identified trials and separately for the low zinc dose and the high zinc dose trials.

Results: Thirteen placebo-controlled comparisons have examined the therapeutic effect of zinc lozenges on common cold episodes of natural origin. Five of the trials used a total daily zinc dose of less than $75 \mathrm{mg}$ and uniformly found no effect. Three trials used zinc acetate in daily doses of over $75 \mathrm{mg}$, the pooled result indicating a $42 \%$ reduction in the duration of colds (95\% CI: $35 \%$ to $48 \%$ ). Five trials used zinc salts other than acetate in daily doses of over $75 \mathrm{mg}$, the pooled result indicating a $20 \%$ reduction in the duration of colds (95\% CI: $12 \%$ to $28 \%$ ).

Conclusions: This study shows strong evidence that the zinc lozenge effect on common cold duration is heterogeneous so that benefit is observed with high doses of zinc but not with low doses. The effects of zinc lozenges should be further studied to determine the optimal lozenge compositions and treatment strategies.
\end{abstract}

Keywords: Meta-analysis, randomized controlled trials, respiratory infections, zinc.

\section{INTRODUCTION}

Zinc has various effects on the immune system and its deficiency increases the risk of infections $[1,2]$. In developing countries, there is evidence that zinc supplementation may reduce the risk of the common cold and pneumonia in children [2-4]. Although such studies indicate that zinc plays an important role in the immune system, those findings cannot be extrapolated to the developed countries where there is no wide spread zinc deficiency. For example, in France and in the UK, multivitamin-mineral tablets containing 15 or $20 \mathrm{mg} /$ day of zinc had no effect on the incidence of respiratory infections of elderly people $[5,6]$.

Interest in zinc lozenges (tablets intended to be dissolved slowly in the mouth) for treating the common cold started from the serendipitous observation that a cold of a 3-year-old girl with leukemia disappeared when she dissolved a therapeutic zinc tablet in her mouth instead of swallowing it [7]. This finding led to a series of controlled trials which have produced conflicting results. The composition of zinc lozenges has varied and some of them contained substances which bind zinc ions tightly. Therefore, a low level of free zinc ions has been considered as one potential factor that might explain divergence in the results [8-15]. The mode of

*Address correspondence to this author at the Department of Public Health, University of Helsinki, Mannerheimintie 172, POB 41, Helsinki, FIN-00014 Finland; Tel: +358-9-191 27573; Fax: +358-9-191 27570;

E-mail: harri.hemila@helsinki.fi action of zinc in the oral cavity is not known. However, the fundamental questions in evaluating a potential treatment should be efficacy, safety and cost, whereas biological explanations and the effects on surrogate outcomes should be secondary issues [16-18].

The purpose of this systematic review is to examine the relationship between the total daily dose of zinc from the lozenges and the effect of the zinc lozenges on the duration of colds in patients who had natural common cold infections.

\section{METHODS}

\section{Search of the Trials}

Ovid MEDLINE (November 24, 2010) was searched using the free search terms "zinc" and "lozenge\$" which retrieved 67 records. The same search terms were used for SCOPUS (November 24, 2010; 107 records) and for the Cochrane Central Register of Controlled Trials (CENTRAL; November 24, 2010; 20 records). No language restrictions were used in the searches. The reference lists of the trials and reviews identified were also perused.

This systematic review was restricted to trials examining the therapeutic effect of zinc lozenges on natural common cold infections. As an inclusion criterion, a concurrent placebo group was required, because clinically relevant common cold outcomes are largely subjective, and explicitly different interventions (i.e., no placebo in one arm) might bias the comparison. Studies with adults and children were both included. Rather than exclude non-randomized trials, 
their influence was considered in a sensitivity analysis. Eleven publications fulfilling the inclusion criteria were identified [7,19-28] (Table 1, see Supplementary Material 1 for a flow diagram of the search and Supplementary Material 2 for a summary of the main characteristics of the included trials). One publication reported three zinc lozenge arms which were compared with one placebo arm [23], so that the number of identified zinc lozenge $v s$ placebo comparisons was 13 (Table 1). One zinc lozenge study was excluded because the lozenge was used with a nasal spray and thus the comparison was not specific to the lozenge [29]. No protocol was written for this systematic review.

To confirm that there are no further trials in addition to those listed in Table 1, a cited reference search was also carried out (Web of Science, November 24, 2010) using the 11 identified publications as cited references, because inaccuracy in coding might hamper the identification of relevant trials in MEDLINE, SCOPUS and CENTRAL. Since all new trials on a given topic most probably refer to one or more earlier trials on the same topic, this provides a further approach for searching the literature. No additional trials were identified by screening the 269 publications that cited the zinc lozenge reports of Table $\mathbf{1}$.

\section{Calculation of the Daily Zinc Dosage}

The total daily dose of elemental zinc from the lozenges was calculated as the product of the zinc dose per lozenge and the counted or planned number of lozenges per day (Table 1; see Supplementary Material 2 for the calculat- ions). In six trials, the number of lozenges was counted [20$22,24-26]$. In the other trials, the usage recommended was the basis for the calculation of the total zinc dosage; for example, description of the dosage as "every $2 \mathrm{hr}$ awake" was interpreted as 9 times per day.

\section{Statistical Methods}

Some earlier reviews on the effect of zinc lozenges on common cold symptoms calculated the effect of zinc on common cold duration on the absolute scale, i.e., as the difference in days in the cold duration $[11,13,14]$. However, Table 1 shows a substantial variation in the duration of colds in the placebo groups, from 5.1 days [22] to 9.0 days [27] and 10.8 days [7]. Although part of this variation is evidently caused by random variation, it is also caused by actual variations in the severity of disease in different patient groups and in differences in outcome definitions. In this study, the relative effect of zinc on the common cold duration was calculated in percentages, because the relative effect partly adjusts for the variations between patient groups and outcome definitions. Previously, the calculation of relative effect instead of the absolute effect led to stronger evidence that vitamin $\mathrm{C}$ supplementation decreases the duration of the common cold [30,31]. Therefore, the relative effect is used in the Cochrane review on vitamin $\mathrm{C}$ and the common cold [32].

Two different approaches were used to evaluate the findings of the zinc lozenge trials: 1) combining the P-values by using the Fisher method [33,34] and 2) pooling the study results by using the RevMan program (version 5) [35].

Table 1. Effect of Zinc Lozenges on Common Cold Episodes of Natural Origin

\begin{tabular}{|c|c|c|c|c|c|c|}
\hline Study [Ref.] & No. of Participants & $\begin{array}{c}\text { Zn Dose } \\
\text { Per Day }(\mathbf{m g})^{\mathrm{a}}\end{array}$ & $\begin{array}{c}\text { Average Duration of Colds (Days) } \\
\text { Zn/Placebo }\end{array}$ & The Effect of $\mathrm{Zn}$ & $\begin{array}{c}\mathbf{P}^{\mathrm{b}} \\
\text { (1-Tail) }\end{array}$ & $-2 \times \ln (\mathrm{P})$ \\
\hline Eby et al.1984 [7] & 65 & 207 & $3.9 / 10.8^{\mathrm{c}}$ & $-64 \%{ }^{\mathrm{c}}$ & $0.0005^{\mathrm{c}}$ & 15.2 \\
\hline Smith et al.1989 [19] & 110 & 207 & $\begin{array}{l}5.9 / 6.3^{\mathrm{d}} \\
5.5 / 6.9^{\mathrm{d}}\end{array}$ & $-22 \%{ }^{d}$ & $\begin{array}{c}0.5^{\mathrm{d}} \\
0.01^{\mathrm{d}}\end{array}$ & 1.4 \\
\hline Godfrey et al. 1992 [20] & 73 & 192 & $4.9 / 6.1$ & $-21 \%$ & 0.024 & 7.4 \\
\hline Prasad et al. 2008 [21] & 50 & 92 & $4.0 / 7.1$ & $-44 \%$ & $6 \times 10^{-13}$ & 56.3 \\
\hline Petrus et al. 1998 [22] & 101 & 89 & $3.8 / 5.1$ & $-26 \%$ & 0.0033 & 11.4 \\
\hline Turner at al. A 2000 [23] & 139 & 80 & $6.0 / 5.5$ & & 0.5 & 1.4 \\
\hline Mossad et al.1996 [24] & 99 & 80 & $4.4 / 7.6$ & $-42 \%$ & 0.0005 & 15.2 \\
\hline Prasad et al. 2000 [25] & 48 & 80 & $4.5 / 8.1$ & $-44 \%$ & $2 \times 10^{-9}$ & 40.0 \\
\hline Turner et al. B 2000 [23] & 139 & 69 & $5.5 / 5.5$ & & 0.5 & 1.4 \\
\hline Douglas et al. 1987 [26] & $58^{\mathrm{e}}$ & 64 & $12.1 / 7.7$ & & 0.96 & 0.1 \\
\hline Macknin et al. 1998 [27] & 247 & 45 & $9.0 / 9.0$ & & 0.5 & 1.4 \\
\hline Weismann et al. 1990 [28] & 130 & 45 & $7 / 6$ & & 0.5 & 1.4 \\
\hline Turner et al. C 2000 [23] & 143 & 30 & $6.0 / 5.5$ & & 0.5 & 1.4 \\
\hline
\end{tabular}

${ }^{\mathrm{a}}$ Calculation of the daily dose of zinc: see Supplementary Material 2 .

${ }^{\mathrm{b}}$ The outcome is the mean or median of common cold duration, except when otherwise stated. The P-values were recalculated when appropriate data was reported in the paper.

${ }^{c}$ Eby et al. [7] did not report the mean or median duration, but estimated the time at which half of the participants were cured from an exponential fit of the results. The P-value at this table was calculated by using the Fisher exact test for the number of participants reporting no symptoms after the 7-day trial: $32 / 37(86 \%)$ and $13 / 28(46 \%)$ in the zinc and placebo groups, respectively.

${ }^{\mathrm{d}}$ Smith et al. [19] reported that "subjects taking zinc gluconate had lower severity scores than those in the corresponding placebo group on days 4 to 7 of treatment. This difference is statistically significant $(\mathrm{P}=0.02)$." From Smith et al.'s fig. 2, the days needed for $80 \%$ reduction in the severity score, which occurred in the 4 to 7 day time range, was measured thereby transforming the effect to the time scale for this table. The upper line (5.9/6.3) gives the interpolated time point when $40 \%$ of participants had become asymptomatic from Smith et al.'s fig. 1; the placebo participants were not followed until half of them had become asymptomatic. To be conservative, $\mathrm{P}=0.5$ was used for calculating the $-2 \times \log (\mathrm{P})$, and not the small P-value corresponding to the difference in severity scores on days 4 to 7 .

${ }^{\mathrm{e}}$ The number of treatment courses was 63 ; some of the 58 participants had more than one cold episode. 
The P-values of Table 1 were combined by using the Fisher method, which is based on the relation that $-2 \times \log (\mathrm{P})$ follows the $\chi^{2}$-distribution with 2 degrees of freedom, with the $\mathrm{P}$-value given in the 1 -tailed form $[33,34]$. Thus, the $-2 \times \log (\mathrm{P})$ values for all selected trials $(\mathrm{N}$ trials) are added, and the total follows the $\chi^{2}$-distribution with $\mathrm{N} \times 2$ degrees of freedom, which gives the combined P-value for all the $\mathrm{N}$ trials. When appropriate data was published, the accurate P-values were calculated. For trials for which the P-value was not reported and could not be calculated, $\mathrm{P}=0.5$ was used, which conservatively assumes equality between the zinc lozenge and the placebo. Extracted or derived P-values are described in Supplementary Material 2. The combined P-values for selected groups of trials are calculated in Table $\mathbf{2}$.

Table 2. The Effect of Zinc Lozenges on the Duration of the Common Cold: Combining the P-Values of the Placebo-Controlled Trials

\begin{tabular}{|l|c|c|c|c|}
\hline \multicolumn{1}{|c|}{ Trials Being Combined } & No. of Trials & $\chi^{2}$ & df & P \\
\hline \hline All trials & 13 & 154.0 & 26 & $10^{-19}$ \\
\hline Low Zn dose $(<75 \mathrm{mg} /$ day $)$ & 5 & 5.7 & 10 & 0.8 \\
\hline High Zn dose $(>75 \mathrm{mg} /$ day $)$ & 8 & 148.3 & 16 & $10^{-22}$ \\
\hline Zn-acetate $[21,22,25]$ & 3 & 107.7 & 6 & $10^{-20}$ \\
\hline not Zn-acetate $[7,19,20,23,24]$ & 5 & 40.6 & 10 & $10^{-5}$ \\
\hline
\end{tabular}

The P-values of the individual trials are combined by using the Fisher method (see the Methods section). The combined $\chi^{2}$ value is calculated from the $-2 \times \ln (\mathrm{P})$ values on the right side of Table 1 . The combined P-values are separately calculated for low dose and high dose trials. Finally, the high dose trials are divided to those which used zinc acetate and to those which used zinc salts other than acetate.

The benefit of the Fisher method of combining P-values is that it can be used for results that are reported on different scales and when limited data is available [33,34]. For example, if one trial reports the duration with its standard deviation (SD) and another trial reports the number of participants who had colds lasting over 7 days, both of them measure the effect on common cold duration, but on different scales. Although no combined effect estimate can be calculated for such trials, the P-values of those two trials can be combined by using the Fisher method. Furthermore, if there is no difference between the study groups e.g. on the basis of considerable overlap in the survival graphs - even though mean and SD are not reported - the study can be included without making any assumptions about the mean and SD, since the lack of difference corresponds to $\mathrm{P}(1$-tail) $=0.5$. Some of the zinc lozenge trials did not report the mean duration of colds and its SD, but they reported the P-values for the comparison of the zinc and placebo groups. For these reasons, the Fisher method was used as one approach to test whether there is a difference between zinc and placebo groups.

A forest plot (Fig. 1) is an efficient way to show the results of several trials, and it was used as a second approach. However, this approach needs the mean and SD values for the zinc and placebo groups. Only three zinc lozenge studies reported the SD values $[21,22,25]$. One study reported the t-value for the comparison [20] and another reported the P-value [26], and the corresponding SD-values were calculated. Nine comparisons were reported as survival graphs, i.e. the number of participants who remained ill or were recovered as a function of time [7,19,23-25,27,28]. These graphs were measured and transformed to the distribution of the duration of colds, which yielded estimates of the mean and SD (Supplementary Material 3). In the analysis of the graphs, several imputations were needed, because the graphs usually did not continue until all patients were recovered. Since the forest-plot analysis required a number of subjective decisions, the Fisher method (above) provided a useful parallel method, because it required less subjective decisions. Nevertheless, sensitivity analyses showed that the conclusions of Fig. (1) are robust to variation in the imputation approach (Supplementary Material 3). The forest plot (Fig. 1) was calculated by using the RevMan program of the Cochrane Collaboration (version 5), using the inverse-variance fixed-effect option [35]. The heterogeneity between trials was assessed by using the $\chi^{2}$ and $\mathrm{I}^{2}$-tests [36]. The $\mathrm{I}^{2}$-test examines the percentage of total variation across studies, that is due to heterogeneity rather than chance. A value of $\mathrm{I}^{2}$ greater than about $75 \%$ indicates a high level of heterogeneity.

\section{RESULTS}

Thirteen placebo-controlled comparisons have examined the therapeutic effect of zinc lozenges on the duration of common cold episodes of natural origin (Table $\mathbf{1}$ and Fig $\mathbf{1}$ ). The total number of common cold episodes in these trials was 1407. All the 13 comparisons were double-blind, although this feature was not a selection criterion. Because of double-blinding, all trials used allocation concealment. Weissman et al. [28] used consecutive allocation, but all the other trials were randomized. All studies examined young and middle-aged adults, except the Macknin et al. [27] trial, which examined schoolchildren.

In Table 1, the trials are ordered by the total daily quantity of elemental zinc obtained from the lozenges. There is a seven-fold variation in the total daily dose of zinc. There is also a considerable variation in the results. Seven comparisons found a statistically significant benefit from zinc lozenges, but six did not.

Smith et al. [19] did not observe a difference between the study groups in the duration of colds; however, they did find a significant reduction in the severity scores on days 4 to 7 of treatment with $\mathrm{P}(1$-tail $)=0.01$. Eby et al. [7] did not report the mean or median duration, but they did report the number of participants who had no symptoms at the end of the 7-day trial, an outcome used for calculating the P-value in Table $\mathbf{1 .}$ The duration of colds given in Table $\mathbf{1}$ for the Eby trial is based on the exponential model which they used to estimate the time at which half of their patients were cured.

Table 1 shows that a substantial proportion of the variation in the results can be explained by the daily zinc dosage. None of the five comparisons that used less than 75 $\mathrm{mg}$ /day of zinc found an effect of zinc lozenges, whereas seven of the eight comparisons which used over $75 \mathrm{mg}$ /day of zinc found a statistically significant benefit, although the benefit in the Smith et al. trial was restricted to the symptom severity at the late phase of the colds.

The P-values of the individual trials are combined by using the Fisher method in Table 2. Combining the P-values of all the 13 comparisons provides very strong evidence that 
Zinc Placebo

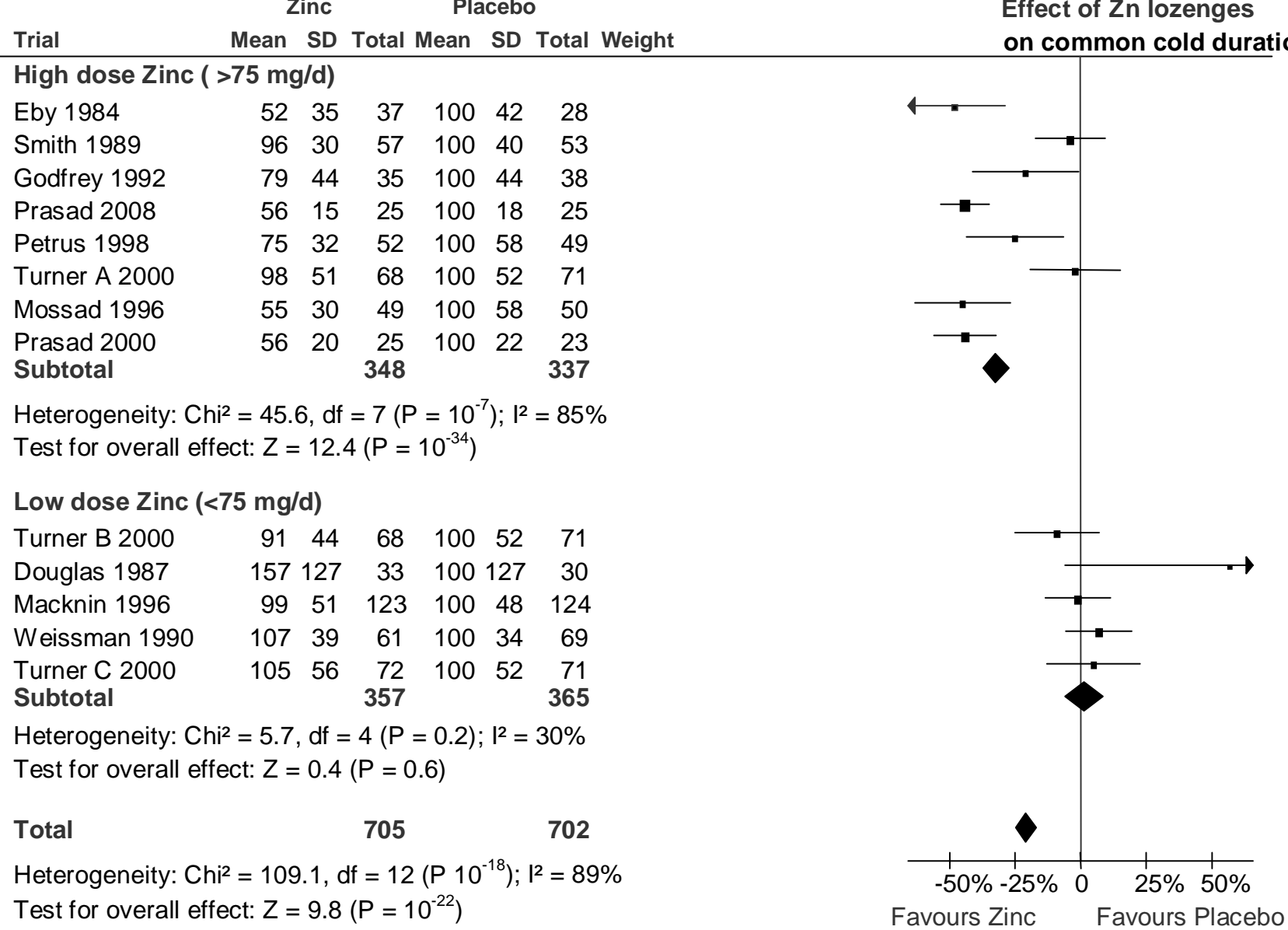

Fig. (1). The effect of zinc lozenges on the duration of the common cold. The trials are in the same order as in Table 1, from the highest daily dose of zinc to the lowest dose. They are divided into the same high dose and low dose subgroups as in Table 2 . In the forest plot on the right side, the vertical line indicates the placebo level. The horizontal line indicates the $95 \%$ CI for the effect and the square in the middle of the horizontal line indicates the point estimate of the effect in the particular trial. Three diamond shapes indicate the pooled effects and their $95 \%$ CI:s for the two subgroups and for all trials. The duration of colds has been transformed to the relative scale so that the duration in the placebo group is given the value of $100 \%$. Thereby the difference between zinc and placebo groups directly indicates the effect of zinc lozenges in percentages. See Supplementary Material 2 and Supplementary Material 3 for the extraction of the data and for the calculation of the relative mean and SD values for the common cold duration.

the zinc lozenge and placebo groups differ over all the trials. However, the benefit of zinc is restricted to trials where the dose was greater than $75 \mathrm{mg} /$ day. A significant effect by zinc lozenges is seen separately in three high-dose trials where zinc acetate was used and in five high-dose trials which used zinc salts other than acetate.

Fig. (1) shows the forest plot of all 13 zinc lozenge comparisons. There is a highly significant heterogeneity between the 13 trials on the basis of both the $\chi^{2}$ and $\mathrm{I}^{2}$-tests, with $\chi^{2}(12 \mathrm{df})=109$ and $\mathrm{I}^{2}=89 \%$. The trials are divided into the low and high dose subgroups as in Table $\mathbf{2}$ and the two subgroups are considerably different in their estimate of the zinc lozenge effect.

In the low-dose trials, there is no evidence of heterogeneity and all the low-dose comparisons are consistent with no effect of zinc lozenges. In the eight highdose trials, the zinc lozenges reduce the duration of colds by $32 \%$ (95\% CI: $27 \%$ to $37 \%$ ) but there is strong evidence of heterogeneity within this high-dose subgroup $\left(\chi^{2}(7 \mathrm{df})=46\right.$ and $\mathrm{I}^{2}=85 \%$ ) (Fig. 1).

Pooling the three high dose $(>75 \mathrm{mg} /$ day) zinc acetate trials gives a mean effect of $42 \%$ reduction in the duration of colds and no heterogeneity is seen between these trials (Table 3). Five high dose ( $>75 \mathrm{mg} /$ day) trials used zinc salts other than acetate $[7,19,20,23,24]$. None of them reported the SD value, but SD was estimated from the published survival curves (Supplementary Material 3) [7,19,23,24] or the reported t-value [20]. Pooling these five non-acetate trials gives a mean effect of $20 \%(95 \% \mathrm{CI}: 12 \%$ to $28 \%)$ reduction in the duration of colds. However, there is significant heterogeneity between these five non-acetate trials $\left(\chi^{2}(4 \mathrm{df})=25.3, \mathrm{P}=0.0001 ; \mathrm{I}^{2}=84 \%\right)$.

Sensitivity analysis by the methodological quality of the trials was not carried out because all trials were doubleblind, which also means that all used concealed allocation. One trial used consecutive allocation [28], but in a doubleblind trial it is not reasonable to assume that consecutive 
Table 3. Pooling the Results of the High Dose Zinc Acetate Trials

\begin{tabular}{|c|c|c|c|c|c|c|c|}
\hline \multirow{2}{*}{ Trial } & \multicolumn{5}{|c|}{ Intervention } & \multicolumn{2}{c|}{$\begin{array}{c}\text { Effect of Zinc Acetate on Common Cold Duration } \\
\text { (95\% CI) }\end{array}$} \\
\cline { 2 - 8 } & \multicolumn{3}{|c|}{ Zinc } & \multicolumn{3}{c|}{ Placebo } \\
\cline { 2 - 8 } & No. of Colds & $\begin{array}{l}\text { Mean Duration } \\
\text { of Colds (Days) }\end{array}$ & SD & No. of Colds & $\begin{array}{c}\text { Mean Duration } \\
\text { of Colds (Days) }\end{array}$ & SD & \\
\hline \hline Petrus et al. $1998[22]^{\mathrm{b}}$ & 52 & 3.80 & 1.63 & 49 & 5.10 & 2.96 & $-26 \%(-44 \%,-7 \%)$ \\
\hline Prasad et al. 2000 [25] & 25 & 4.5 & 1.6 & 23 & 8.1 & 1.8 & $-44 \%(-56 \%,-33 \%)$ \\
\hline Prasad et al. 2008 [21] & 25 & 4.00 & 1.04 & 25 & 7.12 & 1.26 & $-44 \%(-53 \%,-35 \%)$ \\
\hline Pooled results & 102 & & & 97 & & & $-42 \%(-48 \%,-35 \%)$ \\
\hline
\end{tabular}

${ }^{a}$ There is no evidence of heterogeneity over these three trials: $\chi^{2}(2 \mathrm{df})=3.5(\mathrm{P}=0.2), \mathrm{I}^{2}=43 \%$. Calculations were done by using the RevMan program [35].

${ }^{b}$ Petrus et al. [22] reported the results inaccurately to only one decimal place, giving 3.8 and 5.1 for the mean duration of colds and 0.2 and 0.4 for the SE of the mean in the zinc and placebo groups, respectively. These more accurate figures were kindly provided by Ken Lawson (March 4, 2009).

allocation would lead to systematic bias between the study groups. Furthermore, the trial [28] had low dose of zinc and therefore its exclusion would strengthen, and not weaken, the evidence that zinc lozenges differ from the placebo.

All three trials which used zinc acetate in doses higher than $75 \mathrm{mg} /$ day (Table 3) were methodologically rigorous randomized trials $[21,22,25]$. In the Petrus trial, only one participant was lost from follow-up [22]. In the first Prasad trial, two participants in the placebo group dropped out on day 2 [25], whereas there were no drop-outs in the second Prasad trial [21]. No sensitivity analysis was done in this subgroup.

There is substantial heterogeneity within the five highdose non-acetate trials. Sensitivity analysis was done leaving out the Eby et al. [7] and Smith et al. [19] trials, which excluded a large number of randomized participants, $45 \%$ and $36 \%$, respectively. Furthermore, over half of the common cold durations needed to be imputed to include these trials in Fig. (1). When these two trials were excluded from the high-dose non-acetate subgroup, the remaining three trials lead to $22 \%$ (95\% CI: 11 to $32 \%$ ) decrease in the duration of colds. This confidence interval is essentially the same as that for all the five non-acetate trials, see above. Thus, exclusion of these two trials has no influence on conclusions.

\section{DISCUSSION}

\section{Dose-Response Relation Between the Quantity of Zinc and the Effect on the Common Cold Duration}

No effect of zinc lozenges was seen in trials where the total daily dose of zinc was less than $75 \mathrm{mg}$, whereas the majority of trials with higher zinc doses did find benefit (Tables 1 to 3, Fig. 1). The level of $75 \mathrm{mg}$ per day should not be considered as an exact biological limit, but as a pragmatic cut-off point for dichotomizing the trials into low and high dose trials in these meta-analyses. Nevertheless, the conclusion that zinc lozenges differ from the placebo does not depend on the arbitrary cut-off limit because pooling all the 13 double-blind comparisons also shows that zinc lozenges differ from the placebo (Table 2 and Fig. 1).

\section{Lozenge Composition and the Level of Free Zinc Ions}

In these meta-analyses, the dose-response relation was examined using the total daily zinc dose as the explanatory variable. However, this is a simplified approach because some lozenges contained substances which bind zinc ions tightly, such as citrate, tartrate or glycine, which decrease the level of free zinc ions. Thus, even though the same dose of zinc is used in two different lozenges, other constituents may lead to substantial differences in the levels of free zinc ions.

Previously, several authors discussed the availability of zinc ions as a factor that may potentially modify the effect of zinc lozenges on the common cold [8-15]. Martin assumed that sucking a zinc-citric acid lozenge would decrease the $\mathrm{pH}$ of saliva to 2.3 , pointing out that citrate would not form a complex with zinc ion at such a low pH level [10]. However, Zarembo et al. carried out an experiment with 18 participants, finding that sucking a zinc-citric acid lozenge resulted in saliva $\mathrm{pH}$ levels ranging between 3.2 and 5.0 [15]. At such $\mathrm{pH}$ levels citrate binds zinc ions as shown by the published binding curves $[10,11,13,14]$.

The solution chemistry of zinc complexes gives further understanding of the differences between the zinc trials. Two research groups, both using lozenges containing $23 \mathrm{mg}$ of elemental zinc, examined the effect of zinc lozenges on experimentally induced rhinovirus colds. Al-Nakib et al. [37,38] found a significant benefit using the lozenges, whereas Farr et al. found none [39]. However, Farr's lozenge contained $2 \%$ citric acid whereas Al-Nakib's lozenge did not, a difference in lozenge composition which could explain the divergent results [11-14].

Among the trials with natural common cold episodes in Table 1, Godfrey et al. [20] administered a high dose of zinc, but glycine in the lozenge bound $80 \%$ of the zinc ions to complexes [11-14], which could explain the rather small benefit compared with the other trials which used high doses of zinc (Table 1). Turner et al. found no effect using 69 $\mathrm{mg}$ /day of zinc acetate [23]. However, Eby pointed out that Turner's lozenges contained palm kernel and cotton seed oils, and at the high temperature used in the manufacture of the lozenges, these ingredients react with zinc ions making insoluble compounds [40]. The lozenge used by Douglas et al. [26] contained tartaric acid, which binds zinc [11,13,14].

Although the solution chemistry of zinc ions may offer more detailed explanations of the variation between the trial results, the power of the dose-response analysis can be seen even by counting the total daily dosage of elemental zinc obtained from the lozenges (Tables 1 and 2; Fig. 1). 


\section{Safety of Zinc}

In several common cold trials, the zinc lozenges caused acute adverse effects, such as bad taste and constipation, but none of the trials reported long term harm. Furthermore, several of the reported adverse effects, in particular on taste, may have been caused by the specific lozenge composition, and may not reflect the effects of zinc ions per se [13]. In the most recent trial on zinc acetate, there were no significant differences between the zinc and placebo groups in the occurrence of adverse effects although the daily dose was 92 $\mathrm{mg}$ [21].

For certain patients, zinc has been administered at high doses, $150 \mathrm{mg} /$ day, for therapeutic purposes for months or years [41-45]. Deficiency of copper has been reported as a consequence of long-term zinc supplementation [44,45], but a six-week experiment did not find any effect from 150 $\mathrm{mg}$ /day of zinc on plasma copper levels [46]. On the basis of these long-term studies with high zinc doses, there does not seem to be any basis for assuming that treating the common cold for a week with high doses of zinc in the form of lozenges would cause unanticipated harm. A patient suffering from acute adverse effects such as bad taste can simply stop taking the lozenges.

\section{Implications for Further Research}

Table 1 suggests that the benefit of zinc lozenges perhaps can be obtained with doses substantially lower than Eby et al. used in the first trial on the topic [7]. Four trials used 80 to $92 \mathrm{mg}$ of zinc per day and observed significant benefit (Table 1). Three of them used lozenges containing zinc acetate (Table 3), which does not form complexes with zinc ions $[13,14]$. Obviously, new trials should be carried out to confirm the benefit of zinc acetate lozenges at a dosage of about $80 \mathrm{mg}$ per day, and to examine whether even lower daily doses in appropriately formulated lozenges might be effective.

\section{Other Reviews on the Effect of Zinc Lozenges on the Common Cold}

Two groups of reviewers concluded that there is no evidence that zinc lozenges are beneficial against colds. Jackson et al. [47,48] found statistically significant heterogeneity between the zinc trials. They calculated a pooled estimate of effect, although the evidence of heterogeneity seriously challenges the validity of any single overall estimate. Faced with heterogeneous results, the main focus of the reviewers should be on trying to understand the sources of the heterogeneity [49]. Although Jackson suggested that some of the negative results might be explained by low zinc ion availability, they did not examine the issue.

In another systematic review, Caruso et al. used the quality scoring approach, so that for the trials identified they gave one point for each of 11 quality items if it was satisfied [50]. Only four of the identified trials obtained the maximum of 11 points, and Caruso et al. suggested that the positive findings in the zinc trials might be explained by methodological faults. However, such a quality scoring approach is discouraged, for example, in the Cochrane Handbook, which states that "the use of scales for assessing quality or risk of bias is explicitly discouraged in Cochrane reviews. While the approach offers appealing simplicity, it is not supported by empirical evidence" [18].

One major problem of quality scoring is the focus on reporting in contrast to the scientific quality of the trial. For example, Caruso et al. gave one point if the study reported "measurement of dropout rate". This means that a trial can report high dropout rate, indicating low scientific quality, yet Caruso et al. would allot a point because the high dropout rate was explicitly reported. Caruso et al. also gave a point for "double blinding" because "unblinded studies are biased towards finding a treatment effect" [50]. However, such a statement is invalid, because a large meta-analysis of controlled trials found no association between double blinding and the effect of intervention [51]. Most of Caruso et al.'s other quality items involve similar problems. Furthermore, Caruso et al. did not discuss the possibility that the level of free zinc ions might have an effect on the trial results, nor did they refer to any of the numerous papers that have discussed this issue [8-15,52].

Finally, both Jackson et al. [47,48] and Caruso et al. [50] proposed that the benefit of zinc lozenges in some trials might be explained by the placebo-effect. To support their proposal, both groups referred to Chalmers' review on vitamin $\mathrm{C}$ and the common cold, which suggested that the differences between vitamin $\mathrm{C}$ and placebo groups were, paradoxically, caused by the placebo effect [53]. However, Chalmers' review was shown to be erroneous over a decade ago. For example, the figures in his main table were not consistent with the original study reports and he made errors in calculation [30,31,54]. Thus, the conclusions about the effects of zinc lozenges in this study diverge from the conclusions of two earlier reviews, but there are explicit reasons for the divergence in the conclusions.

Goodwin and Tangum [16] argued that within academic medicine there has been systematic bias against the concept that under some conditions micronutrients might be beneficial at levels higher than the minimum required to avoid classic deficiency diseases. Dismissing the randomized double-blind trials in which zinc lozenges significantly reduced the duration of colds gives further support to their thesis.

While this paper was under review, a Cochrane systematic review on zinc and the common cold was published [55]. There are many differences between this paper and the Cochrane review. While this paper strictly limits to zinc lozenges, the Cochrane review combines zinc lozenge trials with ordinary zinc tablet trials. However, it is possible that benefits of zinc tablets [2-4] are caused by particularly low initial zinc intakes of the participants, whereas the effects of zinc lozenges may be caused by local effects in the oral cavity. Nevertheless, the Cochrane review also concluded that there is evidence of benefit of zinc administration.

\section{CONCLUSIONS}

Controlled trials that have examined the effect of zinc lozenges on common cold symptoms have reported divergent results. This meta-analysis shows that a large part of the divergence can be explained by the variation in the total daily dose of zinc that the person obtained from the lozenges. Many trials with daily zinc doses of over $75 \mathrm{mg}$ 
have found significant reduction in the duration of colds. Zinc lozenges have caused adverse effects, such as bad taste, but there is no evidence that they would cause long term harm. Since a large proportion of trial participants have remained without adverse effects, zinc lozenges might be useful for them as a treatment option for the common cold. More research is needed on zinc lozenges to find optimal lozenge compositions and treatment strategies.

\section{SUPPLEMENTARY MATERIAL}

This article contains supplementary material and it can be viewed at publisher's website.

\section{REFERENCES}

[1] Prasad AS. Zinc in human health: effect of zinc on immune cells. Mol Med 2008; 14: 353-7.

[2] Walker FC, Black RE. Zinc and the risk for infectious disease. Annu Rev Nutr 2004; 24: 255-75.

[3] Aggarwal R, Sentz J, Miller MA. Role of zinc administration in prevention of childhood diarrhea and respiratory illnesses: a metaanalysis. Pediatrics 2007; 119: 1120-30.

[4] Kurugöl Z, Akilli M, Bayram N, Koturoglu G. The prophylactic and therapeutic effectiveness of zinc sulphate on common cold in children. Acta Paediatr 2006; 95: 1175-81.

[5] Girodon F, Galan P, Monget AL, et al. Impact of trace elements and vitamin supplementation on immunity and infections in institutionalized elderly patients. Arch Intern Med 1999; 159: 74854.

[6] Avenell A, Campbell MK, Cook JA, et al. Effect of multivitamin and multimineral supplements on morbidity from infections in older people (MAVIS trial): pragmatic, randomised, double blind, placebo controlled trial. BMJ 2005; 331: 324-9.

[7] Eby GA, Davis DR, Halcomb WW. Reduction in duration of common cold by zinc gluconate lozenges in a double-blind study. Antimicrob Agents Chemother 1984; 25: 20-4.

[8] Godfrey JC. Zinc for the common cold. Antimicrob Agents Chemother 1988; 32: 605-6.

[9] Eby GA. Stability constants of zinc complexes affect common cold treatment results. Antimicrob Agents Chemother 1988; 32: 606-7. http://aac.asm.org/cgi/reprint/32/4/606

[10] Martin RB. pH as a variable in free zinc ion concentration from zinc-containing lozenges. Antimicrob Agents Chemother 1988; 32: 608-9.

[11] Eby GA. Zinc ion availability - the determinant of efficacy in zinc lozenge treatment of common colds. J Antimicrob Chemother 1997; 40: 483-93.

[12] Bakar NKA, Taylor DM, Williams DR. The chemical speciation of zinc in human saliva: possible correlation with reduction of the symptoms of the common cold produced by zinc gluconatecontaining lozenges. Chem Spec Bioavailab 1999; 11: 95-101.

[13] Eby GA. Zinc lozenges: cold cure or candy? Solution chemistry determinations. Biosci Rep 2004; 24: 23-39.

[14] Eby GA. Zinc lozenges as cure for the common cold - a review and hypothesis. Med Hypotheses 2010; 74: 482-92.

[15] Zarembo JE, Godfrey JC, Godfrey NJ. Zinc(II) in saliva: determination of concentrations produced by different formulations of zinc gluconate lozenges containing common excipients. J Pharm Sci 1992; 81: 128-30.

[16] Goodwin JS, Tangum MR. Battling quackery: attitudes about micronutrient supplements in American Academic medicine. Arch Intern Med 1998; 158: 2187-91.

[17] Fleming TR, DeMets DL. Surrogate end points in clinical trials: are we being misled? Ann Intern Med 1996; 125: 605-13.

[18] Higgins JPT, Green S, Eds. Cochrane Handbook for Systematic Reviews of Interventions Version 5.1.0 [updated March 2011]. The Cochrane Collaboration, 2011. Sections 5.4.1 and 8.3.3. Available: www.cochrane-handbook.org [Accessed 2011 May 2].

[19] Smith DS, Helzner EC, Nuttall CE Jr, et al. Failure of zinc gluconate in treatment of acute upper respiratory tract infections. Antimicrob Agents Chemother 1989; 33: 646-8.

[20] Godfrey JC, Conant-Sloane B, Turco JH, Mercer N, Godfrey NJ. Zinc gluconate and the common cold: a controlled clinical study. J Int Med Res 1992; 20: 234-46.
[21] Prasad AS, Beck FW, Bao B, Snell D, Fitzgerald JT. Duration and severity of symptoms and levels of plasma interleukin-1 receptor antagonist, soluble tumor necrosis factor receptor, and adhesion molecules in patients with common cold treated with zinc acetate. $\mathrm{J}$ Infect Dis 2008; 197: 795-802.

[22] Petrus EJ, Lawson KA, Bucci LR, Blum K. Randomized, doublemasked, placebo-controlled clinical study of the effectiveness of zinc acetate lozenges on common cold symptoms in allergy-tested subjects. Curr Ther Res 1998; 59: 595-607.

[23] Turner RB, Cetnarowski WE. Effect of treatment with zinc gluconate or zinc acetate on experimental and natural colds. Clin Infect Dis 2000; 31: 1202-8.

[24] Mossad SB, Macknin ML, Medendorp SV, Mason P. Zinc gluconate lozenges for treating the common cold: a randomized, double-blind, placebo-controlled study. Ann Intern Med 1996; 125: 81-8.

[25] Prasad AS, Fitzgerald JT, Bao B, Beck FW, Chandrasekar PH. Duration of symptoms and plasma cytokine levels in patients with the common cold treated with zinc acetate: a randomized, doubleblind, placebo-controlled trial. Ann Intern Med 2000; 133: 245-52.

[26] Douglas RM, Miles HB, Moore BW, Ryan P, Pinnock CB. Failure of effervescent zinc acetate lozenges to alter the course of upper respiratory infection in Australian adults. Antimicrob Agents Chemother 1987; 31: 1263-5.

[27] Macknin ML, Piedmonte M, Calendine C, Janosky J, Wald E. Zinc gluconate lozenges for treating the common cold in children: a randomized controlled trial. JAMA 1998; 279: 1962-7.

[28] Weismann K, Jakobsen JP, Weismann JE, et al. Zinc gluconate lozenges for common cold: a double-blind clinical trial. Dan Med Bull 1990; 37: 279-81.

[29] Eby GA, Halcomb WW. Ineffectiveness of zinc gluconate nasal spray and zinc orotate lozenges in common-cold treatment: A double-blind, placebo-controlled clinical trial. Altern Ther Health Med 2006; 12: 34-8.

[30] Hemilä H, Herman ZS. Vitamin C and the common cold: a retrospective analysis of Chalmers' review. J Am Coll Nutr 1995; 14: 116-23.

[31] Hemilä H. Do vitamins $\mathrm{C}$ and $\mathrm{E}$ affect respiratory infections? Helsinki, Finland: University of Helsinki 2006; 36-8. Available at: https://oa.doria.fi/handle/10024/1540 [Accessed: May 2, 2011].

[32] Hemilä H, Chalker EB, Douglas RM. Vitamin C for preventing and treating the common cold. Cochrane Database Syst Rev 2007: CD000980. doi:10.1002/14651858.CD000980.pub3

[33] Fisher RA. Combining independent tests of significance. Am Stat 1948; 2: 30. Available at: http://digital.library.adelaide.edu.au/coll/ special//fisher/224A.pdf [Accessed: May 2, 2011].

[34] Loughin TM. A systematic comparison of methods for combining p-values from independent tests. Comput Stat Data Anal 2004; 47: 467-85.

[35] Review Manager (RevMan) [Computer program]. Version 5.1. Copenhagen: The Nordic Cochrane Centre, The Cochrane Collaboration, 2011. http://ims.cochrane.org/revman

[36] Higgins JPT, Thompson SG, Deeks JJ, Altman DG. Measuring inconsistency in meta-analysis. BMJ 2003; 327: 557-60.

[37] Al-Nakib W, Higgins PG, Barrow I, Batstone G, Tyrrell DA. Prophylaxis and treatment of rhinovirus colds with zinc gluconate lozenges. J Antimicrob Chemother 1987; 20: 893-901.

[38] Smith AP, Tyrrell DAJ, Al-Nakib W, Barrow I, Higgins P, Wenham R. Effects of zinc gluconate and nedocromil sodium on performance deficits produced by the common cold. J Psychopharmacol 1991; 5(3): 251-4.

[39] Farr BM, Conner EM, Betts RF, et al. Two randomized controlled trials of zinc gluconate lozenge therapy of experimentally induced rhinovirus colds. Antimicrob Agents Chemother 1987; 31: 1183-7.

[40] Eby GA. Elimination of efficacy by additives in zinc acetate lozenges for common colds. Clin Infect Dis 2001; 32: 1520.

[41] Pories WJ, Henzel JH, Rob CG, Strain WH. Acceleration of wound healing in man with zinc sulphate given by mouth. Lancet 1967; 1 : 121-4.

[42] Hallböök T, Laner E. Serum-zinc and healing of venous leg ulcers. Lancet 1972; 2: 780-2.

[43] Simkin PA. Oral zinc sulphate in rheumatoid arthritis. Lancet 1976; 2: 539-42.

[44] Prasad AS, Brewer GJ, Schoomaker EB, Rabbani P. Hypocupremia induced by zinc therapy in adults. JAMA 1978; 240: 2166-8. 
[45] Hoffman HN, Phyliky RL, Fleming CR. Zinc-induced copper deficiency. Gastroenterology 1988; 94: 508-12.

[46] Samman S, Roberts DC. The effect of zinc supplements on plasma zinc and copper levels and the reported symptoms in healthy volunteers. Med J Aust 1987; 146: 246-9.

[47] Jackson JL, Peterson C, Lesho E. A meta-analysis of zinc salts lozenges and the common cold. Arch Intern Med 1997; 157: 23736 .

[48] Jackson JL, Lesho E, Peterson C. Zinc and the common cold: a meta-analysis revisited. J Nutr 2000; 130(5S Suppl): 1512S-5S.

[49] Thompson SG. Why sources of heterogeneity in meta-analysis should be investigated. BMJ 1994; 309: 1351-5.

[50] Caruso TJ, Prober CG, Gwaltney JM. Treatment of naturally acquired common colds with zinc: a structured review. Clin Infect Dis 2007; 45 : $569-74$.
[51] Balk EM, Bonis PA, Moskowitz H, et al. Correlation of quality measures with estimates of treatment effect in meta-analyses of randomized controlled trials. JAMA 2002; 287: 2973-82.

[52] Eby GA. Therapeutic effectiveness of ionic zinc for common colds. Clin Infect Dis 2008; 46: 483-4.

[53] Chalmers TC. Effects of ascorbic acid on the common cold: an evaluation of the evidence. Am J Med 1975; 58: 532-6.

[54] Hemilä H. Vitamin C, the placebo effect, and the common cold: a case study of how preconceptions influence the analysis of results. J Clin Epidemiol 1996; 49: 1079-84.

[55] Singh M, Das RR. Zinc for the common cold. Cochrane Database Syst Rev 2011:CD001364.

(C) Harri Hemilä; Licensee Bentham Open.

This is an open access article licensed under the terms of the Creative Commons Attribution Non-Commercial License (http://creativecommons.org/licenses/ by-nc/3.0/) which permits unrestricted, non-commercial use, distribution and reproduction in any medium, provided the work is properly cited. 